A. M. Demchenko, O. V. Moskalenko, V. V. Sukhoveev, O. I. Barchyna, Yu. A. Fedchenkova

\title{
Synthesis and antiviral activity of 4,6-bis-ethyl- amino[1,3,5]triazine derivatives for Flu A (H1N1) virus California/07/2009
}

\author{
Nizhyn Mykola Gogol State University
}

Key words: Antiviral activity, virus Flu A (H1N1) California/07/2009, Ribavirin, 4,6-bis-ethylamino[1,3,5]triazine derivatives

Epidemics are the type of infectious diseases, which spread significantly faster than expected [1]. Among infectious diseases, almost $90 \%$ of them are caused by influenza viruses. Five pandemics, which occurred in the last century, are related to mutations in strains of influenza HA/ NA. Today, a threat to humanity poses a new SARS-CoV-2 virus [2]. This causes colossal human and resource losses in the world. According to the WHO data, every year, from 3 to 5 millions of people in the world contract severe forms of influenza [3]. Economic losses from it can reach $85 \%$ from all infectious diseases [4-7]. Human losses are no less sensitive during occurrence of a pandemic. For example, pandemic of «Spanish flu» (1918-1919) took from 50 to 100 millions of world people population, «Hong Kong flu» (1968-1970) - more than 1 million, and «Swine flu» (2009-2010, Flu A (H1N1) California/07/2009) - 17 thousands of human lives. From perspective of economic losses and efforts of international community at conducting anti-epidemic measures, the latest was most widespread, but very efficient in terms of human losses.

The fact, that world centers (Atlanta, (USA). Tokio, (Japan). London (Great Britain), Melbourne (Australia) [2], European Centre for Disease Prevention and Control [8] and regional centers and laboratories in more than 140 countries, such as Public Health Surveillance network [9], were created for observation of epidemics, speaks for importance of

(C) Колектив авторів, 2020 importance of said problem. «Centre for public health of the Ministry of health of Ukraine» state institution gained status of National Influenza Center and gained status of GISRS [10].

This is why search for new compounds, that show antiviral activity, is a relevant direction of experimental researches nowadays. 4,6-Bis-ethylamino[1,3,5] triazine derivatives can be perspective in this aspect. Compounds, which show antioxidant [11-13], antitumor [14, 15], anti-inflammatory [16] and antiviral [1724] activities were found among the specified compounds.

The aim of research is to synthesize the 4,6-bis-ethylamino[1,3,5]triazine derivatives and to study the antiviral activity of 2-(4,6-bis-ethylamino[1,3,5] triazine- 2 - yl-sulfanyl) - N - $(2,4,6$ trichlorophenyl)-acetamide for Flu A (H1N1) virus California/07/2009 at primary pharmacological screening stage.

Structural formulas for active ingrediens of Ribavirin, Amizone and 2-(4,6-bisethylamino-[1,3,5]triazine-2-yl-sulfanyl)$\mathrm{N}$-(2,4,6-trichlorophenyl)-acetamide Fig. 1.

Materials and methods. Investigated compounds that are of (4,6-bis-ethylamino-[1,3,5]triazine-2-yl-sulfanyl)-N-arylacetamide derivatives were synthesized in the department of chemistry and pharmacy of Nizhyn Mykola Gogol State University. Compounds 2, 3 a-g, 4 and 5 a-c were synthesized according to the next scheme (Fig. 2).

4,6-Bis-ethylamino-[1,3,5]triazine2-thiol 1 was obtained by the method [25]. Derivatives of appropriated $\alpha$-bromoacetophenones were obtained by brominating of the corresponding acetophenones with bromine in acetic medium. 
<smiles>NC(=O)c1ncn(C2OC(CO)C(O)C2O)n1</smiles>

a

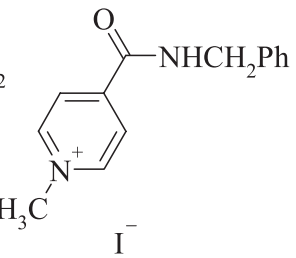

b<smiles>CCNc1nc(NCC)nc(SCC(=O)Nc2c(Cl)cc(Cl)cc2Cl)n1</smiles>

3 c

Fig. 1. Structural formulas for active ingrediens of Ribavirin (a), Amizone (b) and 2-(4,6-bisethylamino-[1,3,5]triazine-2-yl-sulfanyl)-N-(2,4,6-trichlorophenyl)-acetamide (3 c)

Synthesis of 1-(4,6-bis-ethylamino$[1,3,5]$ triazine-2-yl-sulf anyl)-3,3dimethylbutan-2-one 2. $1.79 \mathrm{~g}(0.01 \mathrm{M})$ 1-Bromo-3,3-dimethylbutan-2-one was added to mixture $1.99 \mathrm{~g}(0.01 \mathrm{M})$ of 4,6-bis-ethylamino-[1,3,5]triazine-2-thiol 1 and $3.06 \mathrm{~g}(0.022 \mathrm{M})$ dry $\mathrm{K}_{2} \mathrm{CO}_{3}$ in 80 $\mathrm{ml}$ of ethyl acetate. Refluxed for $5 \mathrm{~h}$, reaction mixture was evaporated to a volume of $20 \mathrm{ml}$ and poured into $200 \mathrm{ml}$ of water. The fallen-out precipitate was filtered off and recrystallized from propanol-2. Yield - $1.64 \mathrm{~g}(55 \%)$. M.p. $=92-93{ }^{\circ} \mathrm{C}$. Found $\%: \mathrm{N} 23.8$. $\mathrm{C}_{13} \mathrm{H}_{23} \mathrm{~N}_{5}$ OS. Calculated, \% N 23.5. ${ }^{1} \mathrm{H}$ NMR (300 MHz, DMSO-d6), $\delta$ (ppm): 1.05 (m, $\left.6 \mathrm{H}, 2\left(\mathrm{NHCH}_{2} \mathrm{CH}_{3}\right)\right), 1.16\left(\mathrm{~s}, 9 \mathrm{H}, \mathrm{C}\left(\mathrm{CH}_{3}\right)_{3}\right)$, $3.22\left(\mathrm{~m}, 4 \mathrm{H}, 2\left(\mathrm{NHCH}_{2} \mathrm{CH}_{3}\right)\right), 4.30(\mathrm{~s}$, $\left.2 \mathrm{H}, \mathrm{COCH}_{2}\right), 5.82\left(\mathrm{~s}, 2 \mathrm{H}, \mathrm{NH}_{2}\right), 7.06-$ $7.27\left(\mathrm{~m}, 2 \mathrm{H}, 2\left(\mathrm{NHCH}_{2} \mathrm{CH}_{3}\right)\right)$.

Synthesis of 2-(4,6-bis-ethylamino$[1,3,5]$ triazine-2-yl-sulfanyl)-N - (2,3- dichlorophenyl)-acetamide 3 a was obtained as compound 2 from $1.99 \mathrm{~g}$ $(0.01 \mathrm{M})$ of 4,6-bis-ethylamino-[1,3,5] triazine-2-thiol $1,2.39 \mathrm{~g}(0.01 \mathrm{M})$ of 2-chloro-N-(2,3-dichlorophenyl)-acetamide and $3.06 \mathrm{~g}(0.022 \mathrm{M})$ of $\mathrm{K}_{2} \mathrm{CO}_{3}$. Yield $3.09 \mathrm{~g}(77 \%)$. M.p. $=172-173{ }^{\circ} \mathrm{C}$. Anal. Calc. for $\mathrm{C}_{15} \mathrm{H}_{18} \mathrm{Cl}_{2} \mathrm{~N}_{6} \mathrm{OS}$. \%: $\mathrm{S}$ 8.00; N 20.9. Found, \%: S 7.88; $\mathrm{N}$ 20.8. ${ }^{1} \mathrm{H}$ NMR (300 MHz, DMSO-d6), $\delta(\mathrm{ppm}): 1.06\left(\mathrm{~m}, 3 \mathrm{H}, \mathrm{NHCH}_{2} \mathrm{CH}_{3}\right), 1.13$ $\left(\mathrm{m}, 3 \mathrm{H}, \quad \mathrm{NHCH}_{2} \mathrm{CH}_{3}\right), 3.25(\mathrm{~m}, 2 \mathrm{H}$, $\left.\mathrm{NHCH}_{2} \mathrm{CH}_{3}\right), 3.29\left(\mathrm{~m}, 2 \mathrm{H}, \mathrm{NHCH}_{2} \mathrm{CH}_{3}\right)$, $3.89\left(\mathrm{~s}, 2 \mathrm{H}, \mathrm{COCH}_{2} \mathrm{~S}\right), 6.98-7.28(\mathrm{~m}, 2 \mathrm{H}$, $\left.2 \mathrm{NHCH}_{2} \mathrm{CH}_{3}\right), 7.31-7.98\left(\mathrm{~m}, 3 \mathrm{H}, \mathrm{C}_{6} \mathrm{H}_{3}\right)$, 9.68 (s, $1 \mathrm{H}, \mathrm{NHCO})$.

Synthesis of 2-(4,6-bis-ethylamino$[1,3,5]$ triazine-2-yl-sulfanyl)- $\mathrm{N}-(2,5-$ dichlorophenyl)-acetamide 3 b was obtained as compound 2 from $1.99 \mathrm{~g}$ $(0.01 \mathrm{M})$ of 4,6-bis-ethylamino-[1,3,5] triazine-2-thiol 1, $2.39 \mathrm{~g}(0.01 \mathrm{M})$ of<smiles>[R]c1ccc(NC(=O)CSc2nc(NCC)nc(NCC)n2)cc1</smiles>

Where 3 : a) $\mathrm{R}=2,3 \mathrm{Cl}_{2}$; b) $\mathrm{R}=2,5 \mathrm{Cl}_{2}$; c) $\mathrm{R}=2,4,6 \mathrm{Cl}_{3}$; d) $\mathrm{R}=2,3\left(\mathrm{CH}_{3}\right)_{2}$; e) $\mathrm{R}=$ $2,4\left(\mathrm{CH}_{3}\right)_{2}$; f) $\mathrm{R}=2,5\left(\mathrm{CH}_{3}\right)_{2}$; g) $\mathrm{R}=4-\mathrm{OPh} .5$ : a) $\mathrm{R}_{1}=\mathrm{H}$; b) $\mathrm{R}_{1}=\mathrm{CH}_{3}$; c) $\mathrm{R}_{1}=\mathrm{OCH}_{3}$.

Fig. 2. Scheme of synthesis of 2-(4,6-bis-ethylamino-[1,3,5]triazine-2-yl-sulfanyl)derivatives (2, 3 $a-g, 4,5 a-c$ ) 
2-chloro-N-(2,5-dichlorophenyl)-acetamide and $3.06 \mathrm{~g}(0.022 \mathrm{M})$ of $\mathrm{K}_{2} \mathrm{CO}_{3}$. Yield 3.41 g $(85 \%)$ ). M.p. $=164-166{ }^{\circ} \mathrm{C}$. Anal. Calc. for $\mathrm{C}_{15} \mathrm{H}_{18} \mathrm{Cl}_{2} \mathrm{~N}_{6} \mathrm{OS}$. \%: $\mathrm{S}$ 8.00; $\mathrm{N}$ 20.9. Found, \%: S 7.85; $\mathrm{N}$ 20.8. ${ }^{1} \mathrm{H}$ NMR (300 MHz, DMSO-d6), $\delta(\mathrm{ppm}): 1.05\left(\mathrm{~m}, 3 \mathrm{H}, \mathrm{NHCH}_{2} \mathrm{CH}_{3}\right), 1.12$ $\left(\mathrm{m}, 3 \mathrm{H}, \mathrm{NHCH}_{2} \mathrm{CH}_{3}\right), 3.21(\mathrm{~m}, 2 \mathrm{H}$, $\left.\mathrm{NHCH}_{2} \mathrm{CH}_{3}\right), 3.29\left(\mathrm{~m}, 2 \mathrm{H}, \mathrm{NHCH}_{2} \mathrm{CH}_{3}\right)$, $3.90\left(\mathrm{~s}, 2 \mathrm{H}, \mathrm{COCH}_{2} \mathrm{~S}\right), 6.97-7.36(\mathrm{~m}, 2 \mathrm{H}$, $\left.2 \mathrm{NHCH}_{2} \mathrm{CH}_{3}\right), 7.17-8.15\left(\mathrm{~m}, 3 \mathrm{H}, \mathrm{C}_{6} \mathrm{H}_{3}\right)$, $9.65(\mathrm{~s}, 1 \mathrm{H}, \mathrm{NHCO})$.

Synthesis of 2-(4,6-bis-ethylamino$[1,3,5]$ triazine-2-yl-sulfanyl)-N-(2,4,6trichlorophenyl)-acetamide $\mathbf{3}$ c was obtained as compound 2 from $1.99 \mathrm{~g}$ $(0.01 \mathrm{M})$ of 4,6-bis-ethylamino-[1,3,5] triazine-2-thiol 1, $2.73 \mathrm{~g}(0.01 \mathrm{M})$ of 2-chloro-N-(2,4,6-trichlorophenyl)-acetamide and $3.06 \mathrm{~g}(0.022 \mathrm{M})$ of $\mathrm{K}_{2} \mathrm{CO}_{3}$. Yield $3.31 \mathrm{~g}(76 \%)$. M.p. $=181-183{ }^{\circ} \mathrm{C}$. Anal. Calc. for $\mathrm{C}_{15} \mathrm{H}_{17} \mathrm{Cl}_{3} \mathrm{~N}_{6} \mathrm{OS}$. \%: $\mathrm{S}$ 7.36; $\mathrm{N}$ 19.6. Found, \%: S 7.48; $\mathrm{N}$ 19.6. ${ }^{1} \mathrm{H}$ NMR (300 MHz, DMSO-d6), $\delta$ (ppm): $1.05\left(\mathrm{~m}, 3 \mathrm{H}, \mathrm{NHCH}_{2} \mathrm{CH}_{3}\right), 1.11$ $\left(\mathrm{m}, 3 \mathrm{H}, \quad \mathrm{NHCH}_{2} \mathrm{CH}_{3}\right), 3.22(\mathrm{~m}, 2 \mathrm{H}$, $\left.\mathrm{NHCH}_{2} \mathrm{CH}_{3}\right), 3.28\left(\mathrm{~m}, 2 \mathrm{H}, \mathrm{NHCH}_{2} \mathrm{CH}_{3}\right)$, $3.89\left(\mathrm{~s}, 2 \mathrm{H}, \mathrm{COCH}_{2} \mathrm{~S}\right), 6.92-7.24(\mathrm{~m}, 2 \mathrm{H}$, $\left.2 \mathrm{NHCH}_{2} \mathrm{CH}_{3}\right), 7.63\left(\mathrm{~s}, 2 \mathrm{H}, \mathrm{C}_{6} \mathrm{H}_{2}\right), 9.81$ (s, $1 \mathrm{H}, \mathrm{NHCO})$.

Synthesis of 2-(4,6-bis-ethylamino$[1,3,5]$ triazine-2-yl-sulfanyl)- $\mathrm{N}-(2,3$-dimethylphenyl)-acetamide $3 \mathrm{~d}$ was obtained as compound 2 from $1.99 \mathrm{~g}(0.01 \mathrm{M})$ of 4,6-bis-ethylamino-[1,3,5]triazine-2-thiol 1, $1.98 \mathrm{~g}(0.01 \mathrm{M})$ of 2-chloro-N-(2,3dimethylphenyl)-acetamide and $3.06 \mathrm{~g}$ $(0.022 \mathrm{M})$ of $\mathrm{K}_{2} \mathrm{CO}_{3}$. Yield $2.81 \mathrm{~g}(78 \%)$. M.p. $=143-145{ }^{\circ} \mathrm{C}$. Anal. Calc. for $\mathrm{C}_{17} \mathrm{H}_{24} \mathrm{~N}_{6}$ OS. \%: S 8.90; N 23.3. Found, \%: $\mathrm{S} 8.75 ; \mathrm{N} 23.5 .{ }^{1} \mathrm{H}$ NMR $(300 \mathrm{MHz}$, DMSO-d6), $\delta$ (ppm): $1.03(\mathrm{~m}, 3 \mathrm{H}$, $\left.\mathrm{NHCH}_{2} \mathrm{CH}_{3}\right), 1.12\left(\mathrm{~m}, 3 \mathrm{H}, \mathrm{NHCH}_{2} \mathrm{CH}_{3}\right)$, $2.05\left(\mathrm{~s}, 3 \mathrm{H}, \mathrm{CH}_{3}\right), 2.24\left(\mathrm{~s}, 3 \mathrm{H}, \mathrm{CH}_{3}\right)$, $3.22\left(\mathrm{~m}, 2 \mathrm{H}, \mathrm{NHCH}_{2} \mathrm{CH}_{3}\right), 3.30(\mathrm{~m}, 2 \mathrm{H}$, $\left.\mathrm{NHCH}_{2} \mathrm{CH}_{3}\right), 3.85\left(\mathrm{~s}, 2 \mathrm{H}, \quad \mathrm{COCH}_{2} \mathrm{~S}\right)$, 6.95-7.03 (m, 3H, $\left.\mathrm{C}_{6} \mathrm{H}_{3}\right), 7.10-7.35(\mathrm{~m}$, $\left.2 \mathrm{H}, 2 \mathrm{NHCH}_{2} \mathrm{CH}_{3}\right), 9.28(\mathrm{~s}, 1 \mathrm{H}, \mathrm{NHCO})$.

Synthesis of 2-(4,6-bis-ethylamino$[1,3,5]$ triazine-2-yl-sulfanyl)-N-(2,4-dimethylphenyl)-acetamide $3 \mathrm{e}$ was obtained as compound 2 from $1.99 \mathrm{~g}(0.01 \mathrm{M})$ of 4,6-bis-ethylamino-[1,3,5]triazine-2-thiol $1,1.98 \mathrm{~g}(0.01 \mathrm{M})$ of 2-chloro-N-(2,4dimethylphenyl)-acetamide and $3.06 \mathrm{~g}$
$(0.022 \mathrm{M})$ of $\mathrm{K}_{2} \mathrm{CO}_{3}$. Yield $2.74 \mathrm{~g}(76 \%)$. M.p. $=147-149{ }^{\circ} \mathrm{C}$. Anal. Calc. for $\mathrm{C}_{17} \mathrm{H}_{24} \mathrm{~N}_{6}$ OS. \%: $\mathrm{S}$ 8.90; N 23.3. Found, \%: $\mathrm{S} 8.83 ; \mathrm{N} 23.2 .{ }^{1} \mathrm{H}$ NMR $(300 \mathrm{MHz}$, DMSO-d6), $\delta$ (ppm): $1.04 \quad(\mathrm{~m}, 3 \mathrm{H}$, $\left.\mathrm{NHCH}_{2} \mathrm{CH}_{3}\right), 1.13\left(\mathrm{~m}, 3 \mathrm{H}, \mathrm{NHCH}_{2} \mathrm{CH}_{3}\right)$, $2.08\left(\mathrm{~s}, 3 \mathrm{H}, \mathrm{CH}_{3}\right), 2.23\left(\mathrm{~s}, 3 \mathrm{H}, \mathrm{CH}_{3}\right)$, $3.24\left(\mathrm{~m}, 2 \mathrm{H}, \mathrm{NHCH}_{2} \mathrm{CH}_{3}\right), 3.31(\mathrm{~m}, 2 \mathrm{H}$, $\left.\mathrm{NHCH}_{2} \mathrm{CH}_{3}\right), 3.82\left(\mathrm{~s}, 2 \mathrm{H}, \quad \mathrm{COCH}_{2} \mathrm{~S}\right)$, 6.91-7.18 (m, 3H, $\left.\mathrm{C}_{6} \mathrm{H}_{3}\right), 7.30-7.43(\mathrm{~m}$, $\left.2 \mathrm{H}, 2 \mathrm{NHCH}_{2} \mathrm{CH}_{3}\right), 9.15(\mathrm{~s}, 1 \mathrm{H}, \mathrm{NHCO})$.

Synthesis of 2-(4,6-bis-ethylamino$[1,3,5]$ triazine-2-yl-sulfanyl)-N-(2,5-dimethylphenyl)-acetamide $3 \mathbf{f}$ was obtained as compound 2 from $1.99 \mathrm{~g}(0.01 \mathrm{M})$ of 4,6-bis-ethylamino-[1,3,5]triazine-2-thiol $1,1.98 \mathrm{~g}(0.01 \mathrm{M})$ of 2-chloro-N-(2,5dimethylphenyl)-acetamide and $3.06 \mathrm{~g}$ $(0.022 \mathrm{M})$ of $\mathrm{K}_{2} \mathrm{CO}_{3}$. Yield $2.84 \mathrm{~g}(79 \%)$. M.p. $=193-194{ }^{\circ} \mathrm{C}$. Anal. Calc. for $\mathrm{C}_{17} \mathrm{H}_{24} \mathrm{~N}_{6}$ OS. \%: S 8.90; N 23.3. Found, \%: $\mathrm{S} 8.74 ; \mathrm{N} 23.5 .{ }^{1} \mathrm{H}$ NMR $(300 \mathrm{MHz}$, DMSO-d6), $\delta$ (ppm): $1.08(\mathrm{~m}, 3 \mathrm{H}$, $\left.\mathrm{NHCH}_{2} \underline{\mathrm{CH}}_{3}\right), 1.11\left(\mathrm{~m}, 3 \mathrm{H}, \mathrm{NHCH}_{2} \underline{\mathrm{CH}}_{3}\right)$, $2.08\left(\mathrm{~s}, 3 \mathrm{H}, \mathrm{CH}_{3}\right), 2.25\left(\mathrm{~s}, 3 \mathrm{H}, \mathrm{CH}_{3}\right)$, $3.27\left(\mathrm{~m}, 2 \mathrm{H}, \mathrm{NHCH}_{2} \mathrm{CH}_{3}\right), 3.32(\mathrm{~m}, 2 \mathrm{H}$, $\left.\mathrm{NHCH}_{2} \mathrm{CH}_{3}\right), 3.84\left(\mathrm{~s}, 2 \mathrm{H}, \mathrm{COCH}_{2} \mathrm{~S}\right)$, 6.83-7.18 (m, 3H, $\left.\mathrm{C}_{6} \mathrm{H}_{3}\right), 7.30-7.41(\mathrm{~m}$, $\left.2 \mathrm{H}, 2 \mathrm{NHCH}_{2} \mathrm{CH}_{3}\right), 9.16(\mathrm{~s}, 1 \mathrm{H}, \mathrm{NHCO})$.

Synthesis of 2-(4,6-bis-ethylamino$[1,3,5]$ triazine-2-yl-sulfanyl)-N-(4 ${ }^{1}$-phenoxyphenyl)-acetamide $3 \mathrm{~g}$ was obtained as compound 2 from $1.99 \mathrm{~g}(0.01 \mathrm{M})$ of 4,6-bis-ethylamino-[1,3,5]triazine-2-thiol $1,2.62 \mathrm{~g}(0.01 \mathrm{M})$ of 2 -chloro-N-( $4^{1}$-phenoxyphenyl)-acetamide and $3.06 \mathrm{~g}(0.022 \mathrm{M})$ of $\mathrm{K}_{2} \mathrm{CO}_{3}$. Yield $3.23 \mathrm{~g}(76 \%)$. M.p. = 134-135 ${ }^{\circ} \mathrm{C}$. Anal. Calc. for $\mathrm{C}_{21} \mathrm{H}_{24} \mathrm{~N}_{6} \mathrm{O}_{2} \mathrm{~S}$. $\%$ : S 7.56; N 19.8. Found, \%: S 7.42; $\mathrm{N}$ 19.9. ${ }^{1} \mathrm{H}$ NMR (300 MHz, DMSO-d6), $\delta$ (ppm): $1.00\left(\mathrm{~m}, 3 \mathrm{H}, \mathrm{NHCH}_{2} \mathrm{CH}_{3}\right), 1.12(\mathrm{~m}$, $\left.3 \mathrm{H}, \mathrm{NHCH}_{2} \mathrm{CH}_{3}\right), 3.23\left(\mathrm{~m}, 2 \mathrm{H}, \mathrm{NHCH}_{2} \mathrm{CH}_{3}\right.$ ), $3.29\left(\mathrm{~m}, 2 \mathrm{H}, \mathrm{NHCH}_{2} \mathrm{CH}_{3}\right), 3.82(\mathrm{~s}, 2 \mathrm{H}$, $\left.\mathrm{COCH}_{2} \mathrm{~S}\right), 6.93-7.58\left(\mathrm{~m}, 9 \mathrm{H}, \mathrm{C}_{6} \mathrm{H}_{5}+\mathrm{C}_{6} \mathrm{H}_{4}\right)$, 6.88-7.17 (m, 2H, $\left.2 \mathrm{NHCH}_{2} \mathrm{CH}_{3}\right), 10.0$ (s, $1 \mathrm{H}, \mathrm{NHCO})$.

Synthesis of 2-(4,6-bis-ethylamino$[1,3,5]$ triazine-2-yl-sulfanyl)- $\mathrm{N}$-isopropyl$\mathbf{N}$-phenyl-acetamide $\mathbf{4}$ was obtained as compound 2 from $1.99 \mathrm{~g}(0.01 \mathrm{M})$ of 4,6-bis-ethylamino-[1,3,5]triazine-2-thiol 1, $2.12 \mathrm{~g}(0.01 \mathrm{M})$ of 2-chloro-N-isopropyl-N-phenyl-acetamide and $3.06 \mathrm{~g}$ $(0.022 \mathrm{M})$ of $\mathrm{K}_{2} \mathrm{CO}_{3}$. Yield $3.23 \mathrm{~g}(82 \%)$. M.p. $=173-174{ }^{\circ} \mathrm{C}$. Anal. Calc. for 
$\mathrm{C}_{18} \mathrm{H}_{26} \mathrm{~N}_{6}$ OS. \%: $\mathrm{S}$ 8.60; $\mathrm{N}$ 22.4. Found, $\%$ : S 8.42; N 22.3. ${ }^{1} \mathrm{H}$ NMR (300 MHz, DMSO-d6), $\delta$ (ppm): $1.01(\mathrm{~m}, 3 \mathrm{H}$, $\left.\mathrm{NHCH}_{2} \mathrm{CH}_{3}\right), 1.03$ (d, 6H, $\left.\mathrm{CH}\left(\mathrm{CH}_{3}\right)_{2}\right)$, $1.14\left(\mathrm{~m}, 3 \mathrm{H}, \mathrm{NHCH}_{2} \mathrm{CH}_{3}\right), 3.09(\mathrm{~m}, 2 \mathrm{H}$, $\left.\mathrm{NHCH}_{2} \mathrm{CH}_{3}\right), 3.47\left(\mathrm{~m}, 2 \mathrm{H}, \mathrm{NHCH}_{2} \mathrm{CH}_{3}\right)$, $3.65\left(\mathrm{~s}, 2 \mathrm{H}, \mathrm{COCH}_{2} \mathrm{~S}\right), 4.30(\mathrm{~m}, 1 \mathrm{H}$, $\left.\underline{\mathrm{CH}}\left(\mathrm{CH}_{3}\right)_{2}\right), \quad 7.25-7.50 \quad\left(\mathrm{~m}, 5 \mathrm{H}, \mathrm{C}_{6} \mathrm{H}_{5}\right)$, 6.65-7.12 (m, 2H, $\left.2 \mathrm{NHCH}_{2} \mathrm{CH}_{3}\right)$.

Synthesis of 2-(4,6-bis-ethylamino$[1,3,5]$ triazine-2-yl-sulfanyl)-1-phenylethanone 5 a was obtained as compound 2 from $1.99 \mathrm{~g}(0.01 \mathrm{M})$ of 4,6-bis-ethylamino-[1,3,5]triazine-2-thiol 1, $1.99 \mathrm{~g}$ $(0.01 \mathrm{M})$ of $\alpha$-bromo-acetophenone and $3.06 \mathrm{~g}(0.022 \mathrm{M})$ of $\mathrm{K}_{2} \mathrm{CO}_{3}$. Yield $2.41 \mathrm{~g}$ $(76 \%)$. M.p. $=115-117{ }^{\circ} \mathrm{C}$. Anal. Calc. for $\mathrm{C}_{15} \mathrm{H}_{19} \mathrm{~N}_{5}$ OS. \% : S 10.1; $\mathrm{N} 22.1$. Found, $\%$ : S 10.0; N 22.0. ${ }^{1} \mathrm{H}$ NMR (300 MHz, DMSO-d6), $\delta$ (ppm): $0.80 \quad(\mathrm{~m}, 3 \mathrm{H}$, $\left.\mathrm{NHCH}_{2} \mathrm{CH}_{3}\right), 1.07\left(\mathrm{~m}, 3 \mathrm{H}, \mathrm{NHCH}_{2} \mathrm{CH}_{3}\right)$, $2.90\left(\mathrm{~m}, 2 \mathrm{H}, \mathrm{NHCH}_{2} \mathrm{CH}_{3}\right), 3.19(\mathrm{~m}, 2 \mathrm{H}$, $\left.\mathrm{NHCH}_{2} \mathrm{CH}_{3}\right), 4.65\left(\mathrm{~s}, 2 \mathrm{H}, \quad \mathrm{COCH}_{2} \mathrm{~S}\right)$, 7.52-8.01 (m, 5H, $\left.\mathrm{C}_{6} \mathrm{H}_{5}\right), 6.95-7.20(\mathrm{~m}$, $\left.2 \mathrm{H}, 2 \mathrm{NHCH}_{2} \mathrm{CH}_{3}\right)$.

Synthesis of 2-(4,6-bis-ethylamino$[1,3,5]$ triazine-2-yl-sulfanyl)-1-phenyl-1para-tolyl-ethanone $\mathbf{5} \mathbf{b}$ was obtained as compound 2 from $1.99 \mathrm{~g}(0.01 \mathrm{M})$ of 4,6-bis-ethylamino-[1,3,5]triazine-2-thiol $2,2.13 \mathrm{~g}(0.01 \mathrm{M})$ of $\alpha$-bromo-4-methylacetophenone and $3.06 \mathrm{~g}(0.022 \mathrm{M})$ of $\mathrm{K}_{2} \mathrm{CO}_{3}$. Yield 2.41 g (86 \%). M.p. = 152-153 ${ }^{\circ} \mathrm{C}$. Anal. Calc. for $\mathrm{C}_{16} \mathrm{H}_{21} \mathrm{~N}_{5} \mathrm{OS}$. $\%$ : S 9.70; N 21.1. Found, \%: S 9.55; $\mathrm{N}$ 21.2. ${ }^{1} \mathrm{H}$ NMR (300 MHz, DMSO-d6), $\delta(\mathrm{ppm}): 0.85\left(\mathrm{~m}, 3 \mathrm{H}, \mathrm{NHCH}_{2} \mathrm{CH}_{3}\right), 1.15$ $\left(\mathrm{m}, 3 \mathrm{H}, \quad \mathrm{NHCH}_{2} \mathrm{CH}_{3}\right), 2.93(\mathrm{~m}, 2 \mathrm{H}$, $\left.\mathrm{NHCH}_{2} \mathrm{CH}_{3}\right), 3.13\left(\mathrm{~m}, 2 \mathrm{H}, \mathrm{NHCH}_{2} \mathrm{CH}_{3}\right)$, $4.20\left(\mathrm{~s}, 2 \mathrm{H}, \mathrm{COCH}_{2} \mathrm{~S}\right), 6.92-7.25(\mathrm{~m}, 2 \mathrm{H}$, $\left.2 \mathrm{NHCH}_{2} \mathrm{CH}_{3}\right), 7.51$ and 7.70 (d-d, $4 \mathrm{H}$, $\mathrm{C}_{6} \mathrm{H}_{4}$ ).

Synthesis of 2-(4,6-bis-ethylamino$[1,3,5]$ triazine-2-yl-sulfanyl)-1-phenyl-1(4'-methoxyphenyl)-ethanone 5 c was obtained as compound 2 from $1.99 \mathrm{~g}$ $(0.01 \mathrm{M})$ of 4,6-bis-ethylamino-[1,3,5] triazine-2-thiol $1,2.13 \mathrm{~g}(0.01 \mathrm{M})$ of $\alpha$-bromo-4-methoxyacetophenone and $3.06 \mathrm{~g}(0.022 \mathrm{M})$ of $\mathrm{K}_{2} \mathrm{CO}_{3}$. Yield $2.78 \mathrm{~g}$ $(80 \%)$. M.p. $=198-199{ }^{\circ} \mathrm{C}$. Anal. Calc. for $\mathrm{C}_{16} \mathrm{H}_{21} \mathrm{~N}_{5} \mathrm{O}_{2} \mathrm{~S}$. \%: $\mathrm{S}$ 9.21; $\mathrm{N} 20.1$. Found, \%: S 9.47; N 20.4. ${ }^{1} \mathrm{H}$ NMR (300 MHz, DMSO-d6), $\delta$ (ppm): 0.87 (m, $\left.3 \mathrm{H}, \mathrm{NHCH}_{2} \underline{\mathrm{CH}}_{3}\right), 1.04$ (m, 3H, $\left.\mathrm{NHCH}_{2} \underline{\mathrm{CH}}_{3}\right)$, $3.05\left(\mathrm{~m}, 2 \mathrm{H}, \mathrm{NHCH}_{2} \mathrm{CH}_{3}\right), 3.17(\mathrm{~m}, 2 \mathrm{H}$, $\left.\mathrm{NHCH}_{2} \mathrm{CH}_{3}\right), 3.85\left(\mathrm{~s}, 3 \mathrm{H}, \mathrm{OCH}_{3}\right), 4.71(\mathrm{~s}$, $\left.2 \mathrm{H}, \quad \mathrm{COCH}_{2} \mathrm{~S}\right), \quad 6.96-7.28(\mathrm{~m}, 2 \mathrm{H}$, $2 \mathrm{NHCH}_{2} \mathrm{CH}_{3}$ ), 7.07 and 8.04 (d-d, $4 \mathrm{H}$, $\overline{\mathrm{C}_{6} \mathrm{H}_{4}}$ ).

Antiviral activity research. Antiviral activity against Flu A H1N1 California/ $07 / 2009$ virus was conducted at the Southern Research Institute (SRI, Birmingham, Alabama, USA) within the framework of an international program to find new antiviral drugs. There were determined the antiviral activity of compound 2-(4,6-bis-ethylamino-[1,3,5]triazine-2-yl-sulfanyl)-N-(2,4,6-trichlorophenyl)-acetamide (3 c) and the active substance of the drug Amizon - iodide 4-(N-benzyl)aminocarbonyl-1-methylpyridinium, an original development of the SI «Institute of Pharmacology and Toxicology of NAMS of Ukraine» [5, 9], which is widely used in Ukraine for the treatment of influenza [10].

The antiviral activity of the tested compounds was evaluated in vitro using MDCK cell culture [26]. According to the procedure Ribavirin is always used at the stage of primary antiviral activity screening as positive control in this test. The cultural medium was grown in a 96-well microplate until the bottom of each well was covered with cells. The residual cultural medium was completely removed and each well was washed twice with phosphate buffer. A solution of Flu A H1N1 in dimethyl sulfoxide (DMSO) was added to each well, adjusted to the required concentration. Then, a compound $3 \mathrm{c}$ or Amizon, or Ribavirin (Sigma), dissolved in DMSO, was added to each well to a final concentration of 0.1 to $10 \mu \mathrm{g} / \mathrm{ml}$. After $48 \mathrm{~h}$ cultivation the state of the culture of MDCK cell was observed in a microscope. Then $100 \mathrm{ml}$ of $70 \%$ acetone was added and each well was kept at $-20{ }^{\circ} \mathrm{C}$ for $1 \mathrm{~h}$. After drying $100 \mathrm{ml}$ of $0.4 \%(\mathrm{w} / \mathrm{v})$ solution of SRB (sulfodoamine B) dissolved in $1 \%(\mathrm{v} / \mathrm{v})$ acetic acid was added. After $30 \mathrm{~min}$ of staining, the non-binding SRB was removed and each well was washed 4 times with $1 \%(\mathrm{v} / \mathrm{v})$ acetic acid. After drying $100 \mu \mathrm{l}$ $10 \mathrm{mM}$ Tris solution ( $\mathrm{pH}$ 10.5) was added to each well to dissolve the colored substance at the bottom of the well. Optical 
Table

Antiviral activity of 2-(4,6-bis-ethylamino-[1,3,5]triazine-2-yl-sulfanyl)-N-(2,4,6trichlorophenyl)-acetamide 3 c against the Flu A (H1N1) virus California/07/2009

\begin{tabular}{|c|c|c|c|c|c|}
\hline Compound & Structure & Type of virus & $\begin{array}{l}\mathrm{EC}_{50} \\
\mu \mathrm{g} / \mathrm{ml}\end{array}$ & $\begin{array}{l}\mathrm{IC}_{50} \\
\mu \mathrm{g} / \mathrm{ml}\end{array}$ & SI \\
\hline $3 \mathrm{c}$ & $\mathrm{CH}_{3} \mathrm{CH}_{2} \mathrm{NH}$ & $\begin{array}{c}\text { Flu A H1N1 } \\
\text { California/07/2009 }\end{array}$ & 0.6 & $>100$ & $>170$ \\
\hline Ribavirin & $\mathrm{HO}$ & $\begin{array}{c}\text { Flu A H1N1 } \\
\text { California/07/2009 }\end{array}$ & 2 & $>320$ & $>160$ \\
\hline $\begin{array}{l}\text { Amizone } \\
\text { (active } \\
\text { ingredient) }\end{array}$ & 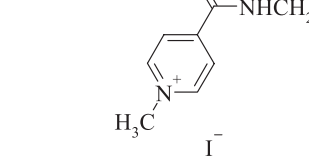 & $\begin{array}{c}\text { Flu A H1N1 } \\
\text { California/07/2009 }\end{array}$ & 47 & $>100$ & $>2.1$ \\
\hline
\end{tabular}

Notes. 1) $E C_{50}$ represents the concentration of a compound where $50 \%$ of the population exhibit a response, after a specified exposure duration. Expressed in $\mu \mathrm{g} / \mathrm{ml} .2$ ) $I_{50}$ is the concentration of a drug that is required for 50 $\%$ inhibition in vitro. Expressed in $\mu \mathrm{g} / \mathrm{ml}$. 3) SI is an index of selectivity, which is an indicator of the effectiveness of the drug, and is expressed by the ratio of $\mathrm{IC}_{50}$ to $\mathrm{EC}_{50}$.

density was measured to evaluate antiviral activity. Cells treated with DMSO only and cells treated with DMSO and the Flu A H1N1 virus were used for control.

Results and discussion. Analysis of the results of antiviral activity against the Flu A (H1N1) virus California/07/2009 virus indicates that compound $3 \mathrm{c}$ with an effective concentration $\left(\mathrm{EC}_{50}\right)$ of $0.6 \mu \mathrm{g} / \mathrm{ml}$ and selectivity index SI $>170$ significantly exceeds such indicators for Ribavirin and Amizon (SI $>160$ and SI $>2.1$, respectively. Under this test system Amizon substance showed much less antiviral activity against the Flu A (H1N1) California/07/2009 virus compared with compound $\mathbf{3} \mathbf{c}$ and was lower than Ribavirin (Table).

Thus, new compound, 2-(4,6-bis-ethylamino-[1,3,5]triazine-2-yl-sulfanyl), provides high antiviral activity against Flu A (H1N1) California/07/2009. The data obtained substantiate the expediency of further studies of 2-(4,6-bis-ethylamino-[1,3,5]triazine-2-yl-sulfanyl) as potential antiviral agents.

\section{Conclusions}

1. New 4,6-bis-ethylamino[1,3,5]triazine derivatives, which can have practical value for search for new antiviral drugs were synthesized.

2. Under in vitro assay on MDCK cell culture compound 3 c exhibits high antiviral activity against the Flu A (H1N1) virus California/07/2009, with an effective concentration $\left(\mathrm{EC}_{50}\right)$ of $0.6 \mu \mathrm{g} / \mathrm{ml}$ and selectivity index SI $>$ 170 that significantly exceeds such indicators for Ribavirin and Amizon (SI $>160$ and SI $>2.1$, respectively).

3 . The data obtained indicate the expediency of further study of derivatives of 2 -(4,6-bis-ethylamino-[1,3,5]triazine2 -yl-sulfanyl) as potential antiviral agents.

Acknowledgement. The authors express their appreciation to the Southern Research Institute (SRI, Birmingham, Alabama) for screening antiviral activity of compounds.

1. Епідемія. URL: https://uk.wikipedia.org/wiki/\%D0\%95\%D0\%BF\%D1\%96\%D0\%B4\%D0\%B5\%D0 \%BC\%D1\%96\%D1\%8F.

2. Спалах коронавірусу SARS-CoV-2. URL: https://uk.wikipedia.org/wiki/\%D0\%A1\%D0\%BF\%D0\%B 0\%D0\%BB\%D0\%B0\%D1\%85_\%D0\%BA\%D0\%BE\%D1\%80\%D0\%BE\%D0\%BD\%D0\%B0\%D0\%B2 \%D1\%96\%D1\%80\%D1\%83\%D1\%81\%D1\%83_SARS-CoV-2. 
3. Розроблення тест-системи для виявлення пандемічного штаму вірусу грипу A (H1N1 2009) за допомогою полімеразної ланцюгової реакції у реальному часі. С. В. Степанюк, М. І. Вудмаска, С. Л. Рибалко, М. Я. Співак. Biotechnologia acta. 2013. V. 6, № 2. С. 85-90.

4. Evolution of HPAI H5N1 virus in Natural ecosystems of Northern Eurasia (2005-2008). D. K. Lvov, M. Yu. Shchelkanov, A. G. Prilipov et al. Avian Dis. 2010. V. 54. P. 483-495.

5. Грипп остается непредсказуемой инфекцией. Д. К. Львов и др. Вопросы вирусологии. 1998. № 3. С. $141-144$.

6. Гендон Ю. З. Пандемия гриппа: можно ли с ней бороться? Вопросы вирусологии. 1998. № 1. С. $43-46$.

7. Супотницкий М. В. Пандемия «Испанки» 1918-1920 гг. в контексте других гриппозных пандемий и «птичьего гриппа». Медицинская картотека. 2006. № 11. С. 31-34.

8. European Centre for Disease Prevention and Control (ECDC). URL: https://www.ecdc.europa.eu/ en/home.

9. The Pacific Public Health Surveillance Network (PPHSN). URL: https://www.who.int/westernpacific/ about/how-we-work/pacific-support/pphsn.

10. ВООЗ надала ЦГЗ статус Національного центру гриппу. URL: https://phc.org.ua/en/node/83.

11. Синтез та антиоксидантні властивості похідних 2-R-(4,6-дипіролідин-1-іл)-[1,3,5]-триазин-2іл)-N-гідразинокарботіоамідів. А. М. Демченко, О. І. Барчина, В. В. Суховєєв та ін. Наукові записки Тернопільського національного педагогічного університету ім. Володимира Гнатюка. Серія: Хімія. 2011. Вип. 18. С. 18-24.

12. Синтез та антиоксидантна активність похідних 4,6-біс-(етиламіно)-2-ацилтіотриазинів-1,3,5. О. І. Барчина, І. В. Геращенко, В. В. Суховєєв та ін. Фармацевтичний журнал. 2011. № 2. C. 56-61.

13. Синтез та антирадикальна ефективність похідних 4,6-диморфоліно-1,3,5-триазинів. О. І. Барчина, А. М. Демченко, В.В.Суховєєв та ін. Фармацевтичний журнал. 2011. № 4. С. 43-49.

14. Патент (на корисну модель) № 94833 Україна, МПК (2014.01) C07D 417/00 A61P 35/00 Заміщені 7-(бензилтіо)-3-трет-бутил-4H-[1,3,4]тіадіазоло[2,3-с] [1,2,4]триазин-4-они, що мають протипухлинну активність. А. М. Демченко, В. О. Янченко, А. О. Акименко, В. В. Суховєєв. № u 2014 03356; Заявл. 02.04.2014; Опубл. 10.12.2014, Бюл. № 23.

15. Патент (на винахід) № 120051 Україна, МПК (2017.01) C07D 251/54 (2006.01), C07D 295/00 (2006.01), А 61K 31/53 (2006.01), А 61K 31/5375 (2006.01), А 61P 35/00. Застосування N-(3,4Диметилфеніл)-6-морфолін-4-іл-N'-(3'-трифлуорометилфеніл)-[1,3,5]триазин-2,4-діаміну як протипухлинного засобу для лікування раку молочної залози підтипу MDA-MB-468. Демченко А. М., Суховєєв В. В., Барчина О. І., Бобкова Л. С. № а 2016 11884; Заявл. 24.11.2016; Опубл. 25.09.2019, Бюл. № 18.

16. Патент (на корисну модель) № 136980 Україна, МПК (2006) C07D 417/00, C07B 43/00,A61P 29/00. 2-(5,7-Біс-етиламіно[1,2,4]триазоло[4,3-а][1,3,5]триазин-3-їл-сульфаніл)-N-(2,4диметоксифеніл)-ацетамід, що має протизапальну дію. Демченко А. М., Барчина О. І., Суховєєв В. В., Ядловський О. Є., Москаленко О. В. № u 2019 02082; Заявл. 01.03.2019; Опубл. 25.09.2019, Бюл. № 18.

17. Патент (на винахід) № 116386 Україна, МПК CO7D 253/065 C07D 295/00 (2013.01) N-(3¹-Хлор$4^{1}$-метилфеніл)-N1-(31-фторфеніл)-6-морфолін-4-їл-[1,3,5]триазин-2,4-діамін, що проявляє антивірусну активність щодо вірусу Middle East Coronavirus (HCoV-EMC). А. М. Демченко, В. В. Суховєєв, Л. С. Бобкова, Ю. В. Ренькас. № а 2016 01111; Заявл. 09.02.2016; Опубл. 12.03.2018, Бюл. № 5.

18. Патент (на винахід) №118704 Україна, МПК : C07D 251/54, A61K 31/53, C07D 413/14, A61K 31/5377. Застосування гідрохлоридів 2,4-диморфоліно-6-ариламіно-[1,3,5]триазинів, як таких, що проявляють антивірусну активність відносно коронавірусу атипової пневмонії SARS. А. М. Демченко, В. В. Суховєєв, О. І. Барчина, Абу Шарк Амжад Ібрагім, Л. С. Бобкова. № а 2017 00319; Заявл. 12.01.2017; Опубл. 25.02.2019, Бюл. № 4.

19. Патент (на винахід) № 118877 Україна, МПК (2006) C07D 253/02 (2006.01), C07D 413/04 (2006.01), А61K 31/5377 (2006.01), А61P 31/12 (2006.01) Застосування похідних N-(41хлорфеніл)-6-морфолін-4-їл-N1-арил-[1,3,5]триазин-2,4-діаміну, як таких, що проявляють противірусну активність щодо вірусу H3N2 штаму Brisbane/10/2007. А. М. Демченко, В. В. Суховєєв, О. І. Барчина, Абу Шарк Амжад Ібрагім, Л. С. Бобкова. № а 2016 12996; Заявл. 20.12.2016; Опубл. 25.03.2019, Бюл. № 6/2019.

20. Патент (на корисну модель) № 133279 Україна, МПК (2006) C07D 253/065 (2006.01), C07D 295/00, A61P 31/12 (2006.01). N,N1-Біс-(21-хлорофеніл)-6-морфолін-4-їл-[1,3,5]триазин-2,4діамін, що проявляє антивірусну активність щодо вірусу Middle East Coronavirus (HCoV-EMC). Демченко А. М., Суховєєв В. В., Барчина О. І., Колесніков О. В., Москаленко О. В. № и 2018 11239; Заявл. 15.11.2018; Опубл. 25.03.2019, Бюл. № 6/2019.

21. Патент (на корисну модель) № 134396 Україна, МПК C07D 253/065 295/00 N-(3,4-дихлорфеніл)N1-(41-етилфеніл)-6-морфолін-4-іл-1,3,5]триазин-2,4-діамін, що проявляє антивірусну 
активність щодо вірусу Middle East Coronavirus (HCoV-EMC). А. М. Демченко, В. В. Суховєєв, О. І. Барчина, С. А. Циганков. № u 2018 12954; Заявл. 27.12.2018; Опубл. 10.05.2019, Бюл. № 9.

22. Патент (на корисну модель) № 135022 Україна, МПК (2006) C07D 487/00, A61K 31/53 (2006.01), A61P 11/00. Гідрохлориди 6-морфолін-4-іл-N-(41-R-феніл)-N1-(мета-толіл)-[1,3,5]триазин2,4-діаміни, що проявляють противірусну активність по відношенню до вірусів H1N1 штаму California/07/2009 та атипової пневмонії SARS. A. М. Демченко, В. В. Суховєєв, О. І. Барчина, О. В. Москаленко, Г. П. Потебня. № u 2019 00405; Заявл. 15.01.2019; Опубл. 10.06.2019, Бюл. № 11.

23. Патент на корисну модель № 137987 Україна, МПК (2006) C07 D 253/065 (2006.01), C07 D 295/00 // N-(3,4-Диметоксифеніл)-N1-(41-фторфеніл)-6-морфолін-4-їл-[1,3,5]триазин-2,4діамін, що проявляє антивірусну активність щодо вірусів MIDDLE EAST CORONAVIRUS (HCOVEMC) та атипової пневмонії SARS. Демченко А. М., Суховєєв В. В., Ренькас Ю. В., Барчина О. І., Москаленко О. В. № и 2019 05172; Заявл. 15.05.2019; Опубл. 11.11.2019, Бюл. № 21/2019.

24. Synthesis and antiviral activity of 2-(4,6-dimorpholine-4-yl-1,3,5-triazine-2-yl)-n-arylhidrazyn-carbothioamids for Flu A H1N1 virus. A. M. Demchenko, O. V. Moskalenko, V. V. Sukhoveev, A. I. Barchyna. Pharmacology and Drug Toxicology. 2019. V. 13 (№ 1). P. 35-41.

25. Patent US 4648898. Hayase Y., Morita K., Ide K., Takahashi T. Triazine derivatives and herbicides. march 101987.

26. Standard Operating Procedure for In Vitro Antiviral Screening. Institute for Antiviral Research, Utah State University. URL: http://arbidol.org/sidwell/NIH_SOP_03-2006.pdf.

\section{A. M. Demchenko, O. V. Moskalenko, V. V. Sukhoveev, O. I. Barchyna, Yu. A. Fedchenkova \\ Synthesis and antiviral activity of 4,6-bis-ethylamino[ $1,3,5]$ triazine derivatives for Flu A (H1N1) virus California/07/2009}

Nowadays, control of viral diseases becomes especially relevant, considering spreading of influenza $A$ (subtype H1N1) in this season and appearance of new coronavirus SARS-CoV-2, which caused their epidemic spreading in the world. This is why development and introduction of new highly effective antiviral drugs are a relevant direction of pharmaceutical chemistry.

The aim of research is to synthesize the derivatives of $(4,6-$ bis-amino[1,3,5]triazin-2-yl-sulphanyl)-Naryl-acetamide and to study the antiviral activity for FluA (H1N1) virus California/07/2009 at primary pharmacological screening stage.

The investigated compounds - (4,6-bis-amino[1,3,5]triazin-2-yl-sulphanyl)- $\mathrm{N}$-aryl-acetamide derivatives, were synthesized on the basis of 4,6-bis-ethylamino[1, 3,5]triazin-2-tiol.

The antiviral activity of (4,6-bis-amino[1,3,5]triazin-2-yl-sulphanyl)- $\mathrm{N}$-(2,4,6-trichlorphenyl)-acetamide against the virus FluA (H1N1) California/07/2009 was evaluated on MDCK cell culture test in vitro. It has been shown that the test substance exhibits high antiviral activity against the influenza $A$ virus $\mathrm{H} 1 \mathrm{~N} 1$ California/ 07/2009 with effective concentration of $\mathrm{EC}_{50} 0,6 \mu \mathrm{g} / \mathrm{ml}$ and the selectivity index $\mathrm{SI}>170$ (for Ribavirin $\mathrm{SI}>160$ and Amizona SI > 2,1).

The data obtained substantiate the expediency of further study of derivatives of $(4,6$-diamino[ $1,3,5]$ triazine-2-yl-sulphanyl)- $\mathrm{N}$-aryl-acetamide as potential antiviral agents.

Key words: antiviral activity, Flu A(H1N1) virus California/07/2009, Ribavirin, Amizon, derivatives of 4,6-bis-ethylamino[1,3,5]triazine

\section{А. М. Демченко, О. В. Москаленко, В. В. Суховєєв, О. І. Барчина, Ю. А. Федченкова}

\section{Синтез і противірусна активність похідних 4,6-біс-етиламіно[1,3,5]триазину щодо вірусу грипу A (H1N1) California/07/2009}

Боротьба з вірусними захворюваннями сьогодні стає особливо актуальною, враховуючи розповсюдження в цьому сезоні грипу А (підтип H1N1) і виникнення нового коронавірусу SARS-CoV-2, що призвело до епідемічного розповсюдження їх у світі. Тому актуальним напрямом фармацевтичної хімії $€$ розробка і впровадження в практику нових високоефективних фармацевтичних препаратів для лікування ГРВІ.

Мета дослідження - синтез і вивчення противірусної активності похідних (4,6-біс-етиламіно-[1,3,5] триазин-2-іл-сульфаніл)-N-арилацетаміду відносно вірусу FluA (H1N1) California/07/2009 на етапі первинного фармакологічного скринінгу.

Досліджувані сполуки - похідні (4,6-біс-етиламіно-[1,3,5]триазин-2-іл-сульфаніл)-N-арилацетаміду було синтезовано на основі 4,6-біс-етиламіно-[1,3,5]триазин-2-тіолу. Оцінено противірусну активність (4,6-біс-етиламіно-[1,3,5]триазин-2-іл-сульфаніл)-N-(2,4,6-трихлорофеніл)ацетаміду in vitro на культурі клітини MDCK з рибавірином як позитивним контролем у цьому тесті.

Показано, що досліджувана речовина виявляє високу противірусну активність відносно вірусу

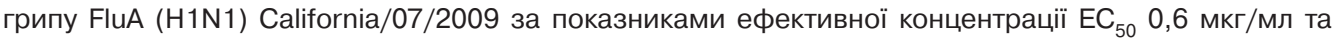
індексом селективності SI > 170 (для Рибавірину SI > 160, Амізону SI > 2,1). 
Отримані дані обґрунтовують доцільність подальшого вивчення похідних (4,6-біс-етиламіно-[1,3,5] триазин-2-іл-сульфаніл)-N-арил-ацетаміду як потенційних противірусних засобів.

Ключові слова: противірусна активність, вірус Flu A (H1N1) California/07/2009, Рибавірин, Амізон, похідні 4,6-біс-етиламіно-[1,3,5]триазину

\section{А. М. Демченко, А. В. Москаленко, В. В. Суховеев, А. И. Барчина, Ю. А. Федченкова \\ Синтез и противовирусная активность производных 4,6-бис-этиламино[1,3,5] триазина по отношению к вирусу гриппа A (H1N1) California/07/2009}

Борьба с вирусными заболеваниями сегодня становится особенно актуальной, учитывая распространение в этом сезоне гриппа А (подтип H1N1) и возникновение нового коронавируса SARSCoV-2, что привело к эпидемическому распространению их в мире.

Поэтому актуальным направлением фармацевтической химии является разработка и внедрение в практику новых высокоэффективных лекарственных препаратов для лечения ОРВИ.

Цель исследования - синтез и изучение противовирусной активности производных (4,6-бисэтиламино-[1,3,5]триазин-2-ил-сульфанил)-N-арилацетамида по отношению к вирусу гриппа Flu A (H1N1) California/07/2009 на этапе первичного фармакологического скрининга.

Исследуемые соединения - производные (4,6-бис-этиламино[1,3,5]триазин-2-ил-сульфанил)$\mathrm{N}$-арилацетамида синтезированы на основе 4,6-бис-этиламино[1,3,5]триазин-2-тиола.

Оценена противовирусная активность (4,6-бис-этиламино[1,3,5]триазин-2-ил-сульфанил)-N(2,4,6-трихлорофенил)ацетамида in vitro на культуре клеток MDCK с рибавирином в качестве позитивного контроля в этом тесте.

Показано, что исследуемое вещество проявляет высокую антивирусную активность по отноше-

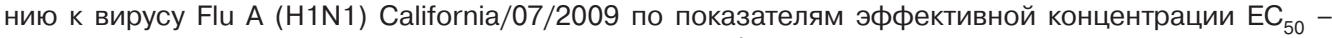
0,6 мкг/мл и индексу селективности - SI > 170 (для Рибавирина SI > 160, Амизона SI > 2,1).

Полученные данные обосновывают целесообразность дальнейшего изучения производных (4,6-бис-этиламино[1,3,5]триазин-2-ил-сульфанил)-N-арилацетамида в качестве потенциальных противовирусных средств.

Ключевые слова: противовирусная активность, вирус Flu A (H1N1) California/07/2009,

Рибавирин, Амизон, производные 4,6-бис-этиламино-[1,3,5]триазина

Надійшла: 11 лютого 2020 p.

Прийнята до друку: 22 квітня 2020 p.

Контактна особа: Москаленко Олег Вадимович, Ніженський державний університет імені Миколи Гоголя, буд. 2, вул. Графська, м. Ніжин, 16600. Тел.: + 380463171967. 